\title{
Mechanical Properties of Composite Materials Made of 3D Stitched Woven-knitted Preforms
}

\author{
HONG HU* \\ Institute of Textiles and Clothing, The Hong Kong Polytechnic University, Hong Kong \\ MINGXING ZHANG \\ College of Textiles, Donghua University, Shanghai 201620, China \\ RAUl FAngueiro AND MARIo de ARAujo \\ School of Engineering, University of Minho, Guimaraes, Portugal
}

\begin{abstract}
This article presents an experimental investigation carried out to understand the mechanical behavior of composite materials made of 3D stitched wovenknitted basalt fabrics. The innovative preforms used consist of two outer layers of a plain woven fabric combined with two inner layers of weft-knitted fabrics. The weft-knitted fabrics selected for the study were varied plain knit, $1 \times 1 \mathrm{rib}$, Milano, and interlock. The fabric layers were stitched together with Kevlar yarns. These 3D stitched preforms were impregnated with polyester resin using resin transfer molding, and the corresponding composites obtained were tested under tensile, bending, and impact loads. The results obtained show that the type of knitted structure significantly influences the mechanical performance of the 3D stitched woven-knitted composites. The composite using interlock structure as the inner layers has the best results concerning energy absorption and tensile strength. The varied plain knit structure has proved to be the best suited to impart stiffness as it provides the highest Young's modulus among the above four knitted structures.
\end{abstract}

KEY WORDS: 3D stitched woven-knitted preforms, mechanical properties, impact behavior, textile composites, stress/strain curves.

\section{INTRODUCTION}

3D TEXTILE PREFORMS ARE used in composite materials to improve their delamination resistance, interlaminar fracture toughness, impact damage resistance, and postimpact mechanical performance [1,2]. 3D textile preforms can be produced by

\footnotetext{
*Author to whom correspondence should be addressed. E-mail: tchuhong@polyu.edu.hk

Figures 1 and 3-8 appear in color online: http://jcm.sagepub.com

Journal of COMPOSITE MATERIALS, Vol. 44, No. 14/2010 
weaving, knitting, braiding, and stitching. In contrast to the typical 3D integral woven, knitted, and braided preforms, stitching is characterized by the insertion of through-the-thickness yarns into traditional 2D preforms as a secondary processing step following lay-up $[3,4]$. The advantages of such through-the-thickness stitching include not only the cost-effective joining of fabrics with an improved ease-of-handling of the dry preform but also improved interlaminar fracture toughness and impact damage resistance of composite parts [4]. To date, the effect of stitching on the mechanical properties of stitched composites has widely been investigated [5-7]. It has been shown that while the out-of-plane impact damage resistance can be improved due to the insertion of the through-the-thickness yarns [8], the in-plane mechanical performance such as tensile strength, tensile modulus, compressive strength, and compressive modulus can be improved, seriously degraded or unchanged depending on the type of composite, the stitching parameters, and the loading conditions [4,5]. Although a few studies show that the stitching improves the in-plane properties by an increase effectively fiber volume fraction parallel to the applied in-plane stresses [4], most investigations report a substantial deterioration due to damage incurred as a results of the stitching process [5]. The damage may occur in various forms including broken fibers, resin-rich regions, and fine-scale resin cracking; however, fiber kinking and misalignment appear to have the greatest detrimental effects on the properties, particularly under tensile and compressive loading [5].

It is necessary to point out that 3D stitched preforms are made by inserting the through-the-thickness yarns into $2 \mathrm{D}$ preforms. For this reason, the mechanical performance of their reinforced composites must be affected by the 2D preforms. However, most investigations found in the literature only focus on the effect of stitching process on the mechanical properties of the composite, few attentions have been paid to the effect of $2 \mathrm{D}$ preforms for stitched composites. Especially, few studies have focused on the combination of different kinds of $2 \mathrm{D}$ preforms in a stitched composite to achieve an optimized reinforcement effect. Today, the commonly used 2D preforms for stitching are still woven fabrics because of their wide application in composite reinforcement [9]. Although the noncrimp fabrics have recently been used as 2D preforms to improve the in-plane mechanical performance of the stitched composite [10,11], 3D stitched preform is still made from a single kind of 2D textile structure. Recently, Sun et al. [12] and, Zhang et al. [13] have suggested to use two different kinds of $2 \mathrm{D}$ textile structures in the same stitched preform for improving energy absorption capacity of the composite under impact. The transversal impacting mechanical properties of both composite material [12] and T-beam structural part [13] made of the stitched biaxial fabric and double-faced interlock preform were experimentally investigated using Hopkinson pressure bar and simulated using finite element analysis. However, their investigations only focused on one kind of knitted structure as the inner layers in stitched preform. Besides, other mechanical properties such tensile and bending properties were not studied.

New section of this study is to investigate the effect of different 3D stitched preforms formed with woven and knitted structures on the mechanical properties of their reinforced composites. As shown in Figure 1, all the 3D stitched preforms used in this study consist of two woven fabrics as the outer layers and two knitted fabrics as the inner layers. The concept of this structure was based on the following considerations when the composite is used for better resistance against impact:

(a) In the front and back layers, the impact stress waves should be quickly transmitted along the panel direction (fabric plane direction) due to the straighter orientation of 


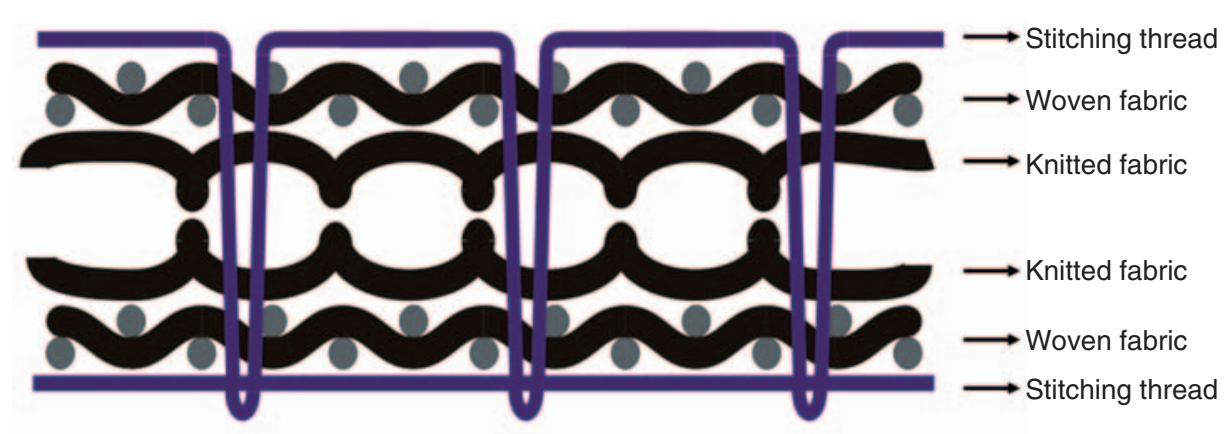

Figure 1. Schematic presentation of $3 D$ stitched woven-knitted structure.

the yarns in the woven fabrics, thus allowing a larger amount of yarns to bear the impact load. Consequently, less damage is expected to be caused by the impact load.

(b) In the inner layers, the knitted fabrics should absorb the transmitted impact stress waves in the thickness direction (perpendicular to the fabric plane direction). Due to the loop structures in the knitted fabrics, larger deformations will take place when the impact load is applied, and therefore, a larger amount of energy can be absorbed.

(c) The stitching yarns play an important role in keeping all fabric layers together. When the impact load is applied to the composite, compression on the upper half and extension on the bottom half of the panel will take place, and therefore, the stitching yarns can help to avoid delamination from occurring.

In this article, the tensile, bending, and low-velocity impact properties of the composites made of different knitted fabric structures as the inner layers of 3D stitched preforms will be presented.

\section{EXPERIMENTAL DETAILS}

\section{Preparation of 3D Stitched Preforms}

One kind of woven fabric and four kinds of knitted fabrics were used to fabricate 3D stitched preforms according to the structure shown in Figure 1. The woven fabric used was a plain weave made of basalt filaments. It was provided by Hengdian Group Shanghai Russia \& Gold Basalt Fiber Co. Ltd in Shanghai. The structural parameters of the plain weave are listed in Table 1. The four knitted fabrics used were, respectively, produced with varied plain knit, $1 \times 1$ rib, interlock, and Milano (Figure 2) on a STOLL CMS E10 electronic flat-knitting machine made in Germany. All the knitted fabrics were made of 280 tex basalt filament. Their structural parameters are listed in Table 2. Table 3 shows the four kinds of 3D stitched preforms made by combining the above woven and knitted fabrics. The preforms were only varied by changing their inner knitted fabric structures and by keeping constant the woven fabric structure used in the outer layers. As shown in Figure 3, all 3D preforms were stitched with 350 tex Kevlar129 yarn into square forms. This kind of stitching was selected because the stitching space in both weft and warp directions are the same. Also, the stitching process was easily realized with the existing equipment. Only one stitch density 
Table 1. Structural parameters of the plain woven fabric.

\begin{tabular}{lll}
\hline & Warp yarns & Weft yarns \\
\hline Yarn linear density (tex) & 316 & 323 \\
Density (yarns $/ \mathrm{cm})$ & 6.2 & 6.2 \\
Crimp (\%) & 4 & \\
Mass per unit area $\left(\mathrm{g} / \mathrm{m}^{2}\right)$ & 461 & \\
\hline
\end{tabular}

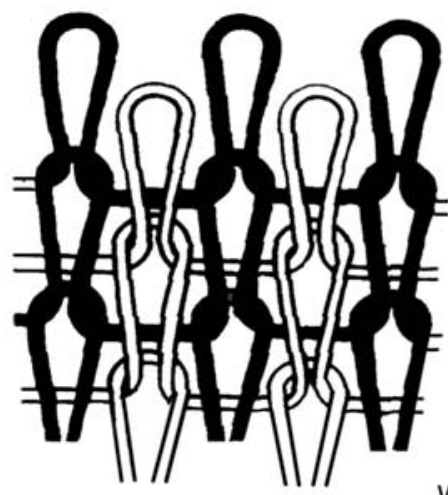

(a)

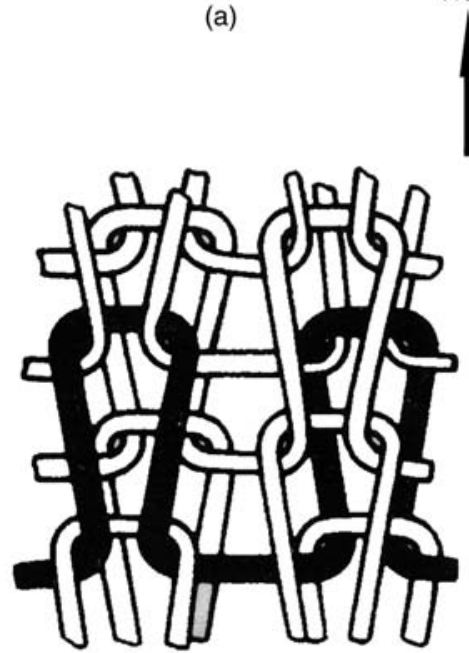

(c)

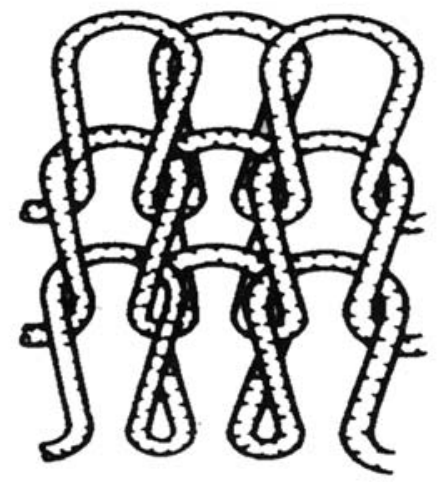

(b)

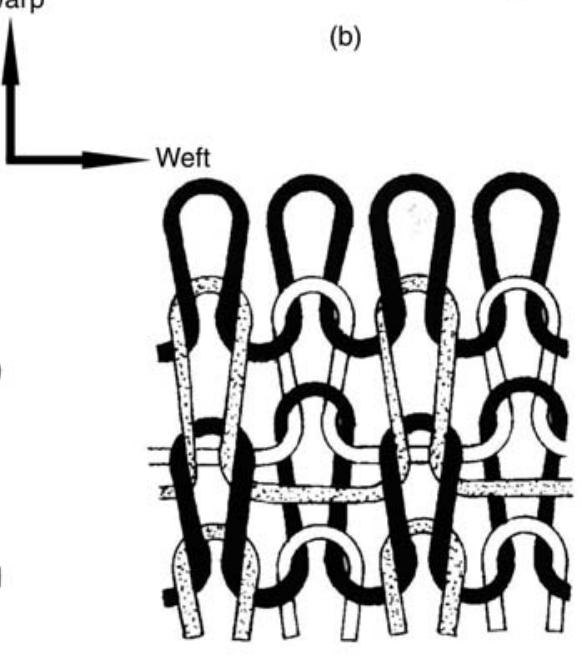

(d)

Figure 2. Knitted structures used: (a) varied plain knit, (b) $1 \times 1$ rib, (c) interlock, and (d) Milano.

(1 square stitch $/ \mathrm{cm}^{2}$ ) was used. The weft and warp directions of all fabrics were kept the same for all the stitched preforms.

Fabrication of Composite Samples

A vinyl ester resin was used to produce the composite samples through resin transfer molding (RTM). Methyl ethyl ketone peroxide was used as catalyst and cobalt 
Table 2. Structural parameters of the knitted fabrics.

\begin{tabular}{lccccc}
\hline & $\begin{array}{c}\text { Weft density } \\
(\text { wales/cm) }\end{array}$ & $\begin{array}{c}\text { Warp density } \\
(\text { courses/cm) }\end{array}$ & $\begin{array}{c}\text { Loop length } \\
(\mathbf{m m})\end{array}$ & $\begin{array}{c}\text { Tightness } \\
\text { factor }\left(\frac{\sqrt{\text { tex }}}{\text { loop length }}\right)\end{array}$ & $\begin{array}{c}\text { Mass per } \\
\text { unit area }\left(\mathbf{g} / \mathbf{m}^{2}\right)\end{array}$ \\
\hline Varied plain knit & 6.6 & 5.0 & 1.52 & 11.05 & 1852 \\
$1 \times 1$ rib & 3.6 & 5.0 & 2.78 & 6.19 & 1420 \\
Interlock & 7.2 & 7.0 & 1.39 & 12.04 & 2123 \\
Milano & 4.4 & 6.2 & 2.27 & 7.37 & 1517 \\
\hline
\end{tabular}

Table 3. 3D stitched preforms.

\begin{tabular}{lll}
\hline Stitched preforms & Outer layers & Inner layers \\
\hline P1 & Plain weave & Interlock \\
P2 & Plain weave & Varied plain knit \\
P3 & Plain weave & Milano \\
P4 & Plain weave & $1 \times 1$ rib \\
\hline
\end{tabular}

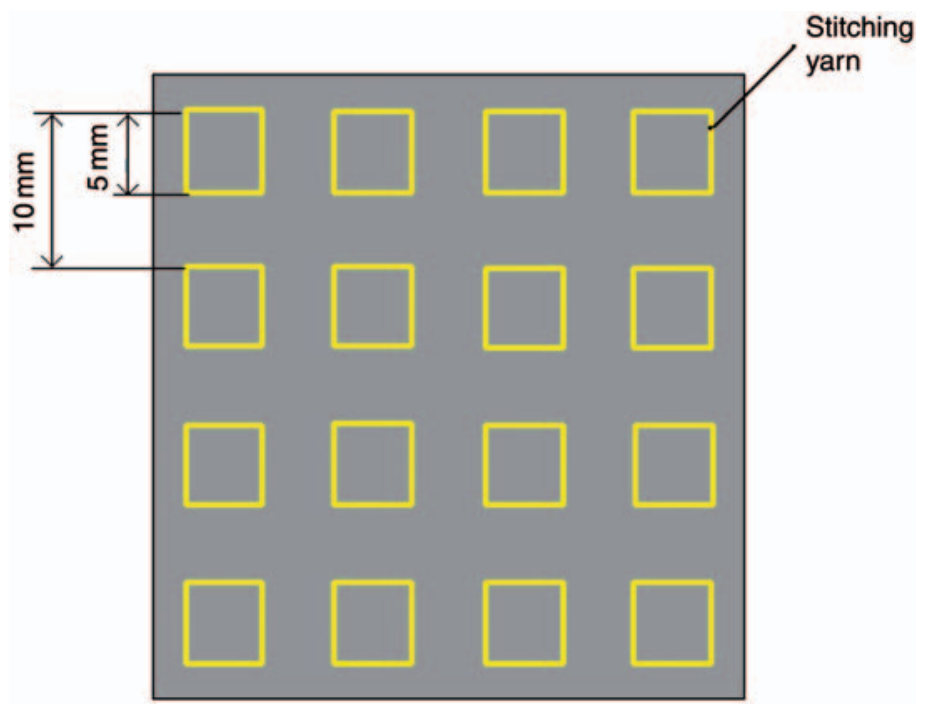

Figure 3. Stitching scheme.

2-ethylhexanoate as accelerator. The ratio of resin, catalyst, and accelerator was $100: 2: 1$ by weight, respectively. All composite samples were cured for $24 \mathrm{~h}$ at room temperature followed by $8 \mathrm{~h}$ of postcuring in an oven at $80^{\circ} \mathrm{C}$. A composite sample that was fabricated is shown in Figure 4. The specifications of the composite samples made with the four different 3D stitched are listed in Table 4. It was found that the composite using an interlock as the inner layers has the highest fiber volume fraction and thickness because interlock has the highest mass per unit area and the highest tightness factor among all four knitted fabrics used. Here, the tightness factor is defined as the ratio of the square root of yarn linear density in tex and loop length in a unit cell of the fabric structure. 


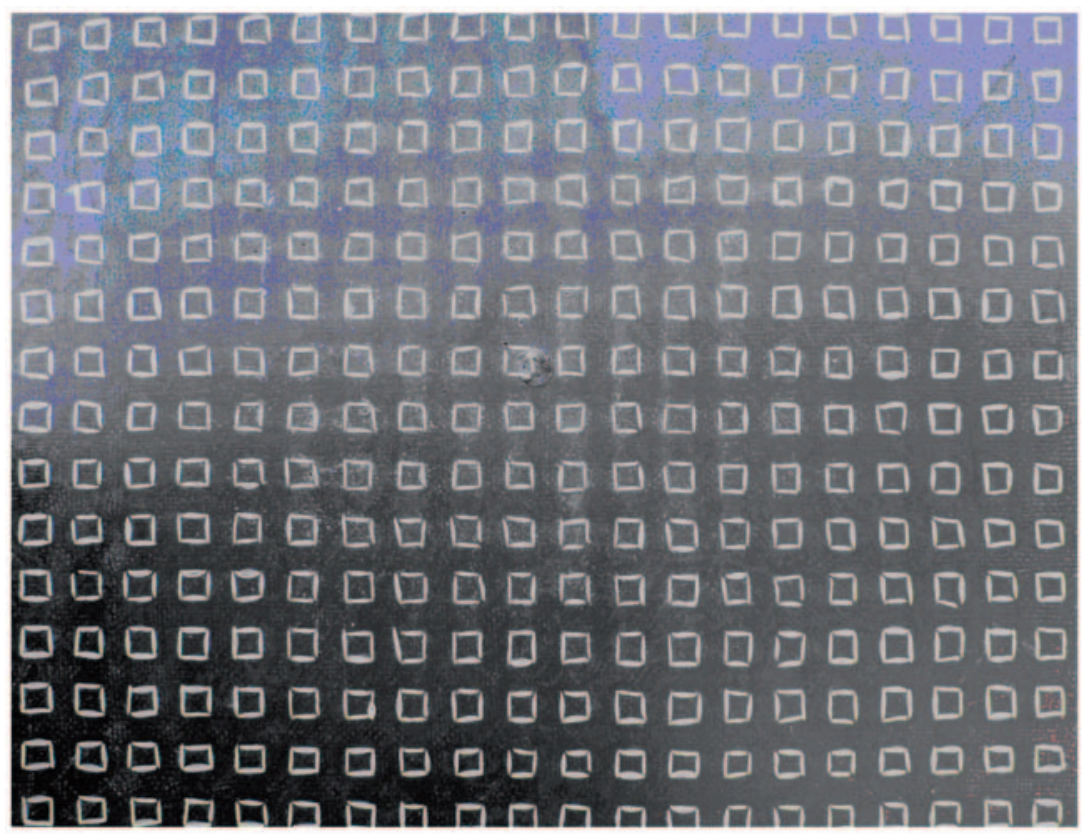

Figure 4. Photograph of a $3 D$ stitched woven-knitted basalt composite.

Table 4. Specifications of the composite samples.

\begin{tabular}{lccc}
\hline $\begin{array}{l}\text { Composite } \\
\text { samples }\end{array}$ & Preforms & $\begin{array}{c}\text { Fiber volume } \\
\text { fraction }(\%)\end{array}$ & $\begin{array}{c}\text { Thickness } \\
(\mathbf{m m})\end{array}$ \\
\hline C1 & P1 & 42 & 5.3 \\
C2 & P2 & 40 & 5.2 \\
C3 & P3 & 39 & 4.9 \\
C4 & P4 & 38 & 5.0 \\
\hline
\end{tabular}

\section{Tensile Testing}

Composite samples for tensile tests were prepared according to the ASTM D3039/ D3039M-07 standard. Five $50 \mathrm{~mm}$ long and $25 \mathrm{~mm}$ wide rectangular samples were prepared for each testing direction (weft and warp). Tensile tests were conducted on a Hounsfield H100KS Universal Tensile Tester with a crosshead speed of $2 \mathrm{~mm} / \mathrm{min}$, using an extensometer to measure the deformation.

\section{Three-Point Bending Testing}

Three-point bending tests were also conducted on the Hounsfield H100KS Universal Tensile Tester, according to the ASTM D790-3 standard, with a crosshead speed of $2 \mathrm{~mm} / \mathrm{min}$. Five $200 \mathrm{~mm}$ long and $5 \mathrm{~mm}$ wide samples were prepared for each testing direction (weft and warp). The set span length $l$ (the distance of two support points) was 16 times of the thickness for all the samples. After testing, the following 
equations were used for calculating the bending modulus and bending stress of each sample, respectively:

$$
\begin{aligned}
E_{f} & =\frac{l^{3} \Delta P}{4 b h^{3} \Delta f} \\
\sigma_{f} & =\frac{3 P l}{2 b h^{2}},
\end{aligned}
$$

where $E_{f}$ is the bending modulus, $\sigma_{f}$ is the bending stress, $P$ is the load applied at the central point of the sample, $\Delta P$ is the increment of $P, \Delta f$ is the central deflection increment, $b$ and $h$ are the width and thickness of the sample, respectively.

\section{Impact Testing}

An Imatek impact testing system was used to evaluate the low-velocity impact behavior of the $3 \mathrm{D}$ stitched composites under transverse loads. Square samples of $75 \times 75 \mathrm{~mm}^{2}$ were used for the tests with three different dropping speeds $(3.13,3.83$, and $4.43 \mathrm{~m} / \mathrm{s})$, which correspond to three different dropping heights $(0.5,0.75$, and $1 \mathrm{~m})$ of the impactor. The relation between the dropping speed and the impactor's height is given by the following equation:

$$
v=\sqrt{2 g h}
$$

where $v$ is the dropping speed $(\mathrm{m} / \mathrm{s}), g$ is the acceleration of gravity $\left(\mathrm{m} / \mathrm{s}^{2}\right)$, and $h$ is the impactor's height (initial vertical distance between the surface of the sample and the impactor (m)).

\section{RESULTS AND DISCUSSION}

\section{Tensile Testing}

The results obtained from tensile tests in both the warp and weft directions are shown in Table 5 and Figure 5, respectively, for the composite samples made with all four 3D stitched preforms. By analyzing the data and curves, the following important points are noted:

(1) The variations of the stress with increases of the strain for all four composites are not totally linear. A yield point for each curve can be observed at the earlier stage of strain. This phenomenon is normal as the yarns in both the woven and knitted structures are not totally straight. The yarn crimp in the woven structure and the loop shape in the knitted structure resulted in this nonlinearity of the composites. On the other hand, the crimped yarns will increase deformation of the composites. This can be confirmed as the strains at fracture for all the composite samples are higher than those of the fibers used. The strains at fracture of the basalt filament and Kevlar129 used in this study were 0.031 and 0.033 , respectively. These values are lower than the minimal strain value 0.038 of the composites shown in Table 5. The higher strains can make the composites absorb more tensile energy.

(2) All the composites have higher strength at fracture in the warp direction than in the weft direction. This phenomenon can be explained by the fact that all the knitted fabrics are constructed with loops. As a loop has two legs (two yarns) in the warp direction, but only has one yarn in the weft direction, more yarns are oriented in the warp direction than in the weft direction in a knitted fabric. Consequently, composites 
Table 5. Tensile testing results.

\begin{tabular}{|c|c|c|c|c|c|c|c|c|}
\hline \multirow[b]{2}{*}{$\begin{array}{l}\text { Composite } \\
\text { sample }\end{array}$} & \multicolumn{2}{|c|}{$\begin{array}{c}\text { Young's } \\
\text { modulus (GPa) }\end{array}$} & \multicolumn{2}{|c|}{$\begin{array}{c}\text { Stress at } \\
\text { fracture (MPa) }\end{array}$} & \multicolumn{2}{|c|}{$\begin{array}{c}\text { Strain at } \\
\text { fracture (-) }\end{array}$} & \multicolumn{2}{|c|}{$\begin{array}{l}\text { Specific tensile } \\
\text { energy }\left(k J / \mathrm{m}^{3}\right)\end{array}$} \\
\hline & $\begin{array}{c}\text { Warp } \\
\text { direction }\end{array}$ & $\begin{array}{c}\text { Weft } \\
\text { direction }\end{array}$ & $\begin{array}{c}\text { Warp } \\
\text { direction }\end{array}$ & $\begin{array}{c}\text { Weft } \\
\text { direction }\end{array}$ & $\begin{array}{c}\text { Warp } \\
\text { direction }\end{array}$ & $\begin{array}{c}\text { Weft } \\
\text { direction }\end{array}$ & $\begin{array}{c}\text { Warp } \\
\text { direction }\end{array}$ & $\begin{array}{c}\text { Weft } \\
\text { direction }\end{array}$ \\
\hline C1 & 22.2 & 18.9 & 617 & 247 & 0.063 & 0.042 & 22,268 & 8025 \\
\hline C2 & 29.0 & 21.4 & 564 & 230 & 0.052 & 0.028 & 18,570 & 5409 \\
\hline C3 & 17.8 & 16.8 & 328 & 214 & 0.050 & 0.046 & 11,174 & 7648 \\
\hline C4 & 19.3 & 18.2 & 265 & 224 & 0.044 & 0.038 & 8086 & 5824 \\
\hline
\end{tabular}
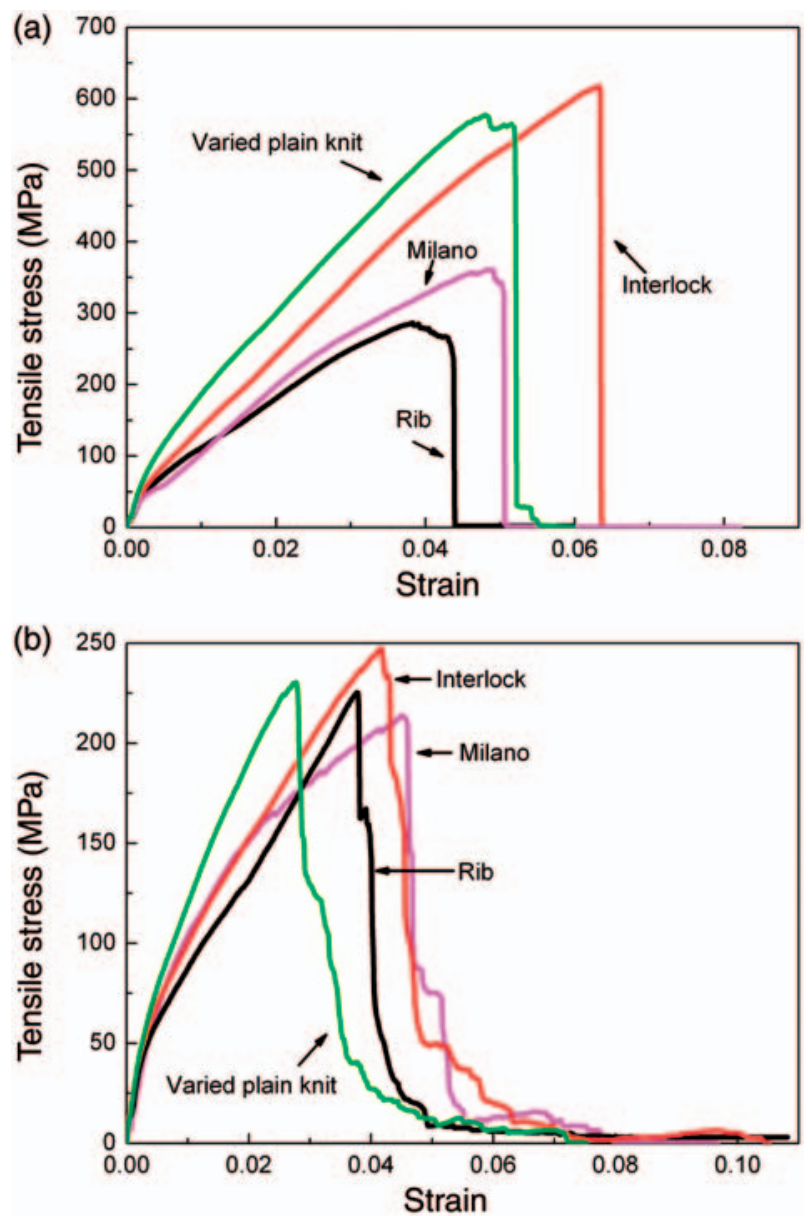

Figure 5. Tensile stress-strain curves: (a) warp direction and (b) weft direction.

reinforced with knitted structures have better mechanical performance in the warp direction than in the weft direction. It is necessary to point out that as loop shape can be changed in different knitted structure, the difference of the tensile strength and modulus between the warp and weft directions for all composites can be different depending on the knitted structure used. Observing Table 5, it was found that the 
difference of the mechanical performance between the warp and weft directions for the composites made with an interlock and varied plain knit as the inner layers is bigger than that of the composites made with Milano and rib as the inner layers because more yarns are oriented in the warp direction in interlock and varied plain knit.

(3) The composite using an interlock structure as the inner layers has the highest strengths and specific tensile energy in both the warp and weft directions, whereas the composite using varied plain knit has the lowest strain at fracture in the weft direction and the highest modulus in both the warp and weft directions. As shown in Figure 2, the interlock structure is formed with two ribs. It has the tightest loop structure and highest tightness factor so that the composite made with interlock as the inner layers has the highest fiber volume fraction. As the mechanical performance of a composite mainly depends on the fiber volume fraction when yarn orientations in the loops do not have significant changes, the composite made with interlock as the inner layers has the highest strengths and specific tensile energy in both the warp and weft directions. However, the varied plain knit has better yarn orientation in both the warp and weft directions due to longer yarn floats, which are formed by longer loop legs in the warp direction and longer sinker loops between two adjoining loops in the weft direction (Figure 2(a)). The higher yarn orientations in the varied plain knit result in higher Young's modulus and lower strains of the composite.

It is necessary to point out that although the plain-woven structure and weft-knitted structures have different deformation behaviors, stitching them together can limit their difference of deformation under tension in the composite. As shown in Figure 5(a) and (b), the sharp drops in the stress level to almost zero observed after fracture for all the composite samples indicates that the different woven and knitted reinforced layers in a composite were broken at the same time. This means that no difference of the deformation existed among these woven and knitted reinforced layers. Consequently, no delaminations occurred in the composite. This phenomenon can be explained by the fact that stitching keeps both the woven and knitted structure as an integrated structure and thus reduces their difference when subjected to extension.

From the tensile tests, it is possible to conclude that using an interlock as the inner layers in the $3 \mathrm{D}$ stitched preform can get the highest tensile strength of the reinforced composite because the $3 \mathrm{D}$ stitched preform made with interlock as the inner layers has the highest fiber volume fraction.

\section{Three-Point Bending Testing}

The results of the three-point bending tests for all the composite samples in the warp and the weft directions are shown in Table 6 and Figure 6, respectively. The values of the bending modulus and bending stress listed in Table 6 were calculated according to Equations (1) and (2).

Analyzing the results obtained, it was found that in the warp direction, the 3D stitched composite made with varied plain knit as the inner layers presents the highest bending modulus, and the 3D stitched composite made with interlock as the inner layers has the highest bending strength. Moreover, the 3D stitched composite made with interlock as the inner layers shows the highest ability to absorb bending energy. Both the composites made with Milano and rib as the inner layers show lower bending strength and stiffness. It was also found that in the weft direction, the composite made with varied plain knit as 
the inner layers has the highest bending modulus, whereas the composite made with interlock as the inner layers has the highest bending strength. The results also show that the composite made with the same knitted structure as the inner layers always has better performance in the warp direction than in the weft direction. All these variation trends in three-point bending tests are very similar to the case of tensile tests because the composites were made with the same 3D stitched preforms.

Table 6. Bending testing results.

\begin{tabular}{|c|c|c|c|c|c|c|c|c|}
\hline \multirow[b]{2}{*}{$\begin{array}{l}\text { Composite } \\
\text { sample }\end{array}$} & \multicolumn{2}{|c|}{$\begin{array}{c}\text { Bending } \\
\text { modulus (GPa) }\end{array}$} & \multicolumn{2}{|c|}{$\begin{array}{c}\text { Bending } \\
\text { strength (MPa) }\end{array}$} & \multicolumn{2}{|c|}{$\begin{array}{l}\text { Deflection at } \\
\text { fracture }(\mathrm{mm})\end{array}$} & \multicolumn{2}{|c|}{$\begin{array}{l}\text { Specific bending } \\
\text { energy }\left(\mathbf{k J} / \mathbf{m}^{3}\right)\end{array}$} \\
\hline & $\begin{array}{c}\text { Warp } \\
\text { direction }\end{array}$ & $\begin{array}{c}\text { Weft } \\
\text { direction }\end{array}$ & $\begin{array}{l}\text { Warp } \\
\text { direction }\end{array}$ & $\begin{array}{c}\text { Weft } \\
\text { direction }\end{array}$ & $\begin{array}{l}\text { Warp } \\
\text { direction }\end{array}$ & $\begin{array}{c}\text { Weft } \\
\text { direction }\end{array}$ & $\begin{array}{l}\text { Warp } \\
\text { direction }\end{array}$ & $\begin{array}{c}\text { Weft } \\
\text { direction }\end{array}$ \\
\hline $\mathrm{C} 1$ & 29.3 & 11.23 & 468 & 282 & 5.882 & 6.652 & 3618 & 1125 \\
\hline C2 & 30.5 & 21.01 & 433 & 254 & 2.749 & 4.949 & 3107 & 1494 \\
\hline C3 & 20.4 & 15.87 & 340 & 233 & 7.502 & 7.832 & 1361 & 1281 \\
\hline C4 & 12.6 & 12.27 & 273 & 172 & 6.303 & 6.848 & 1352 & 752 \\
\hline
\end{tabular}
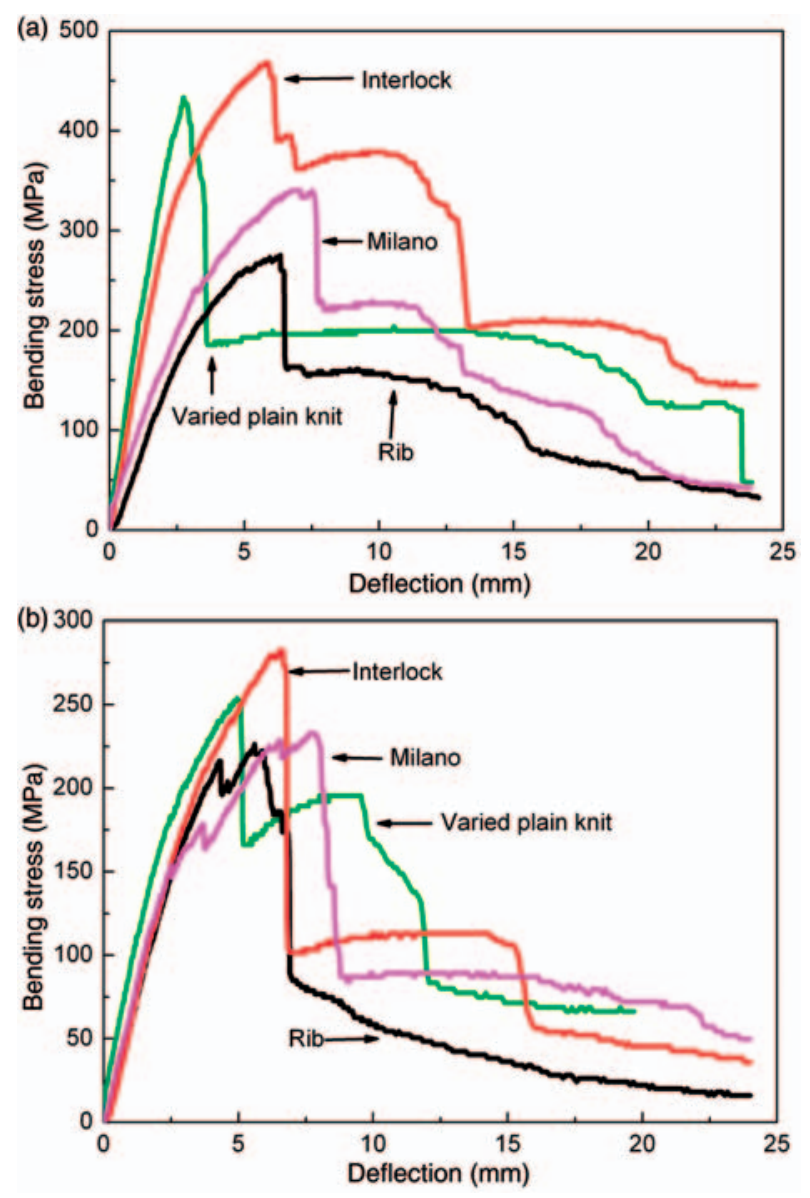

Figure 6. Bending stress-deflection curves: (a) warp direction and (b) weft direction. 
However, a special phenomenon needs to be mentioned in the three-point bending tests. Analyzing the stress-deflection curves, it was found that the step-like drops in stress tend to occur after the maximal tensile strength is achieved due to the earlier break of the outer surface woven layer that has smaller deformation ability. The curve for the composite made with interlock in the warp direction clearly shows the step sequence of breaking of the structures, which occurs first at the outer woven layer, followed by the bottom knitted layer, then the upper knitted layer, and finally the inner woven layer. To avoid the step-like drops, the bottom outer layer fabric should have higher deformation ability than inner layers. In this case, using the woven fabric as the outer layer is not a good choice for bending as the woven fabric has lower deformation ability than knitted fabric.

\section{Impact Testing}

As explained before, the 3D stitched preforms were designed to withstand impact loads by combining the advantages of both the woven and knitted structures. Although the straight yarns in the woven structure are used to transmit the impacting stress waves in a larger area, the loops in the knitted structures are used to absorb the impacting energy. For this reason, drop impact testing was carried out in this work to assess the impact performance of the composites made with this kind of 3D stitched preforms.

The load-displacement curves for all four kinds of composite samples tested with three different impacting speeds $(3.13,3.38$, and $4.43 \mathrm{~m} / \mathrm{s})$ are shown in Figure $7(\mathrm{a})-(\mathrm{c})$, respectively. According to these curves, it is possible to divide the impact into two main stages as follows: compression deformation and rebounding of the samples. The compression
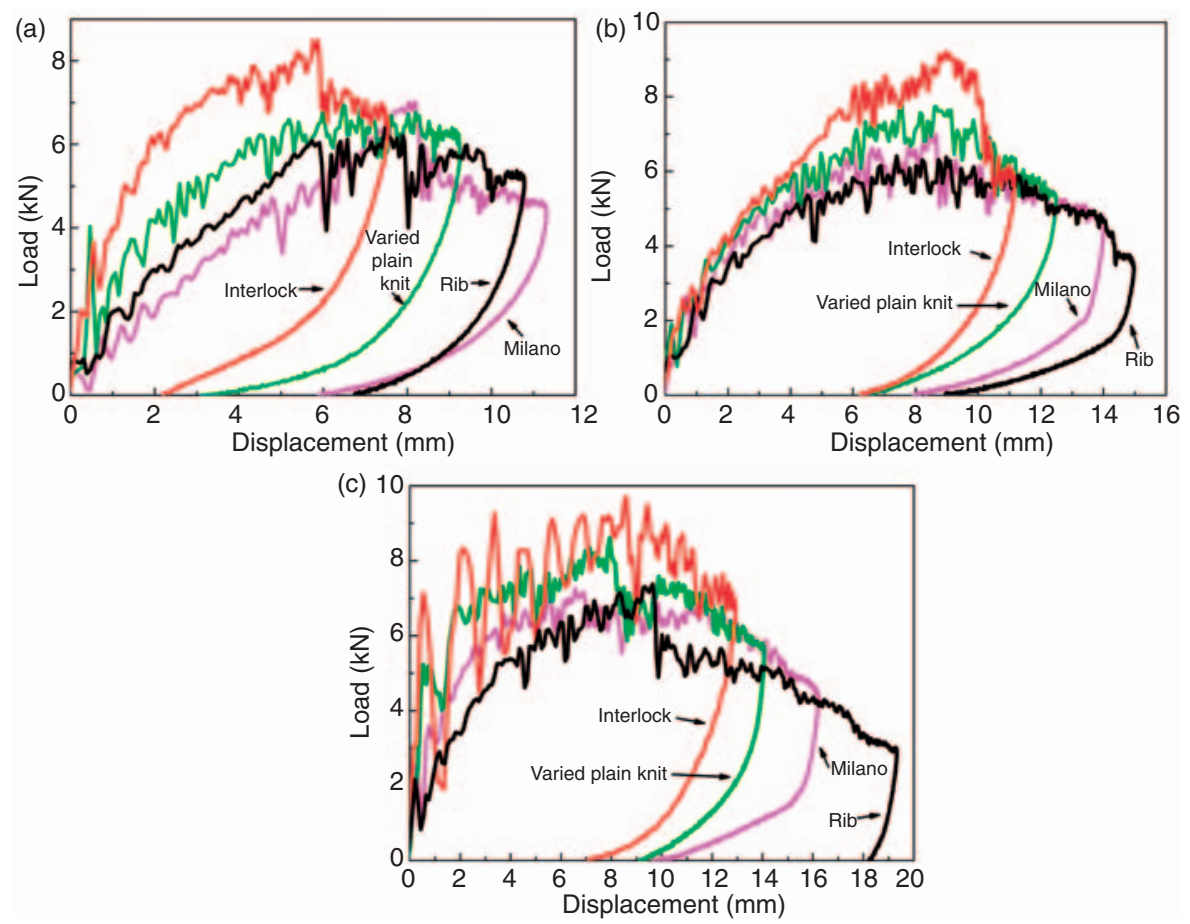

Figure 7. Load-displacement curves under different impacting speeds: (a) $3.13 \mathrm{~m} / \mathrm{s}$, (b) $3.83 \mathrm{~m} / \mathrm{s}$, and (c) $4.43 \mathrm{~m} / \mathrm{s}$. 
deformation can further be split into different phases. At the initial impact, the load linearly increases as the displacement increases. This is due to the elastic deformation of the composite under low load. At that time, the stress wave produced from impact can propagate along the surface layer rapidly due to the straighter yarns arrangement of the woven fabric. With increase of the displacement, matrix cracking occurs and propagates, followed by damage of the interface matrix/fiber. As the load continues to increase, the basalt filaments and aramid stitching yarns are stretched and breakage of the fibers occurs as they are no longer able to bear the load. It is necessary to point out that all the load-displacement curves in the compression deformation stage do not smoothly increase and sawtooth fluctuations are observed. This phenomenon is due to the asynchronicity of breakage of the different layers and different yarns.

In order to compare the influence of knitted structure on the performance of the composites against impact, the specific energies absorbed by each composite under different impact speeds were analyzed and their variations with displacement are shown in Figure 8(a)-(c), respectively. Two stages of the impact can very clearly be identified from these curves. The first stage corresponds to the energy absorption of the composite samples, and the second stage corresponds to the release of the energy. It was found that the composite made with the interlock as the inner layers shows the best impact energy absorption ability. This can be explained by its double-layer-like interlock-knitted structure. The interlock structure presents $\pm 45^{\circ}$ out-of-plane yarn orientation, which increases the yarns/fiber directions for energy propagation. For this reason, the composite reinforced with interlock possess higher specific energy absorption ability. As explained before, interlock is formed with
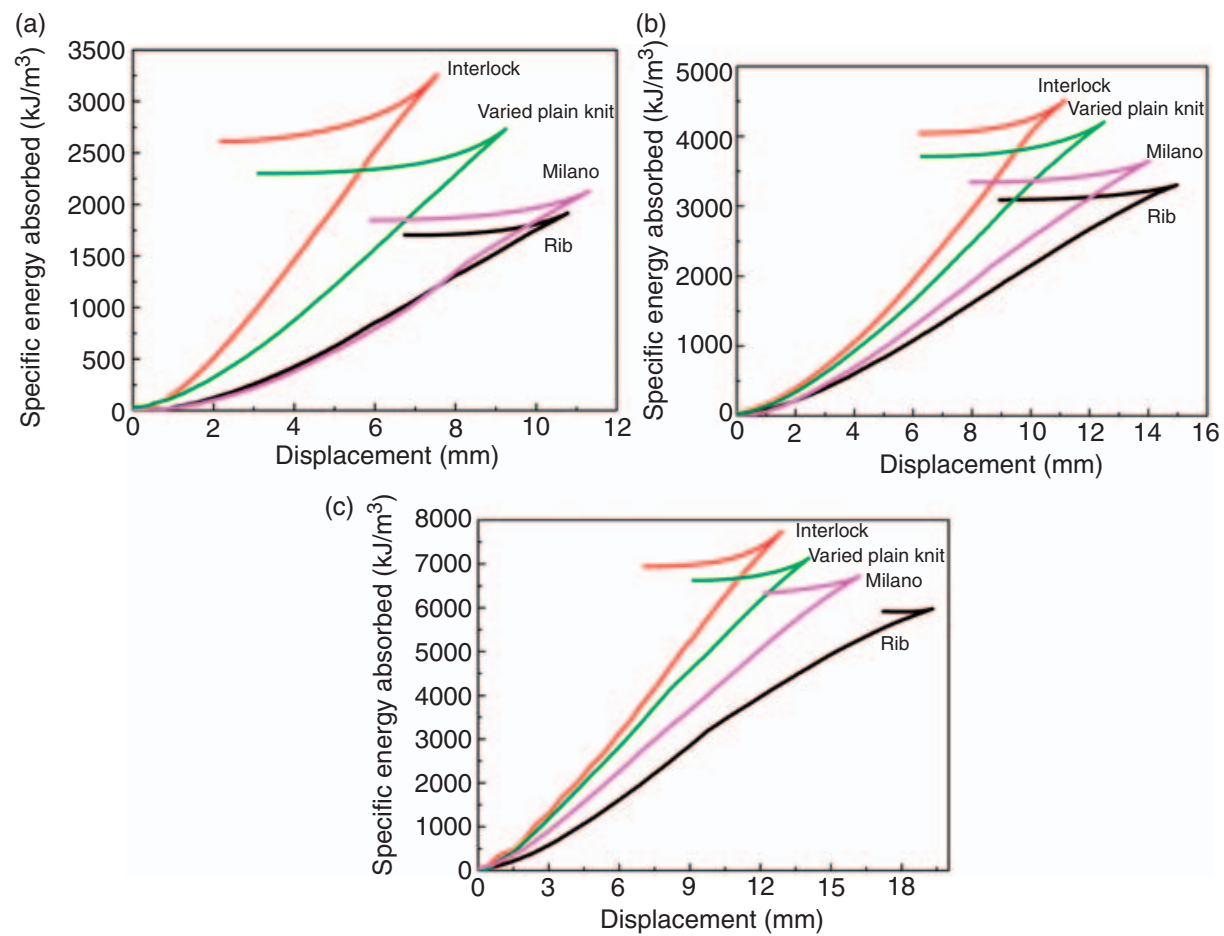

Figure 8. Specific energy absorbed-displacement curves under different impacting speeds: (a) $3.13 \mathrm{~m} / \mathrm{s}$, (b) $3.83 \mathrm{~m} / \mathrm{s}$, and (c) $4.43 \mathrm{~m} / \mathrm{s}$. 
two $1 \times 1$ rib structures intermeshed with crossed loops. It seems that the yarns in these crossed loops play an important role in impact energy absorption.

The results presented in Figure 7 and Figure 8 also show the influence of the impacting speeds on the deformation and energy absorption of the 3D stitched composite samples. In order to clearly illustrate this influence, the two sides (front and back) of the impacted composite samples under different impacting speeds were photographed and are shown in Figure 9. It is found that the plastic deformation after impacting increases with increase of the initial height of the impactor, that is, initial impacting speed.
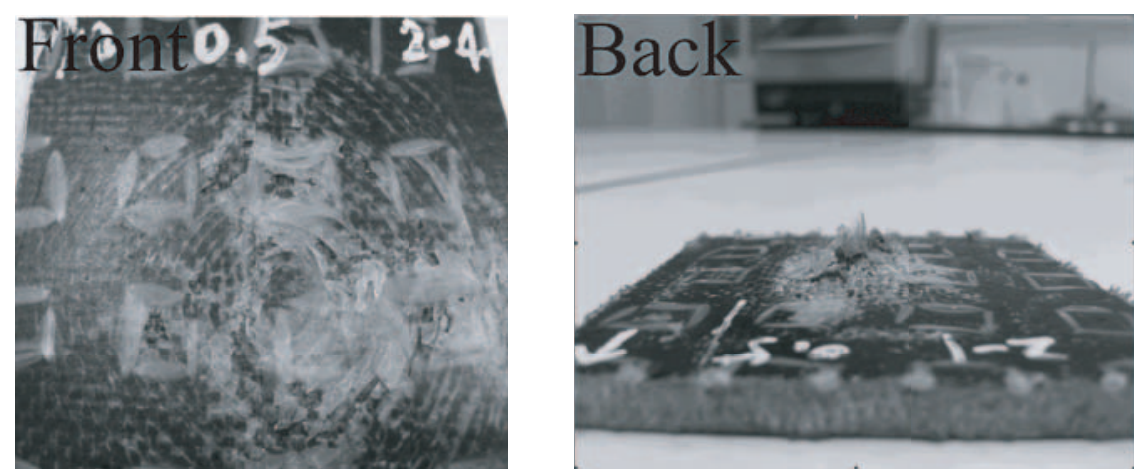

(a)
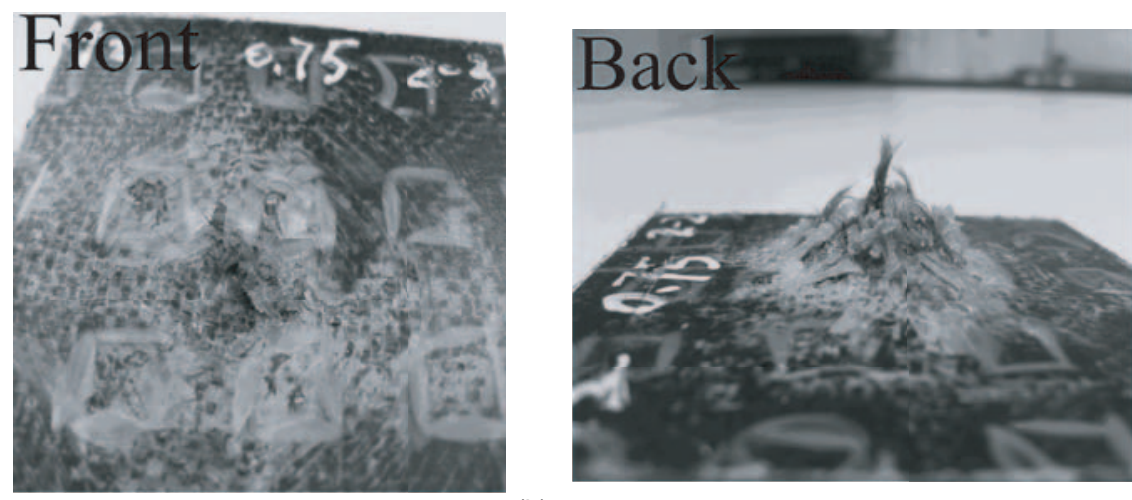

(b)
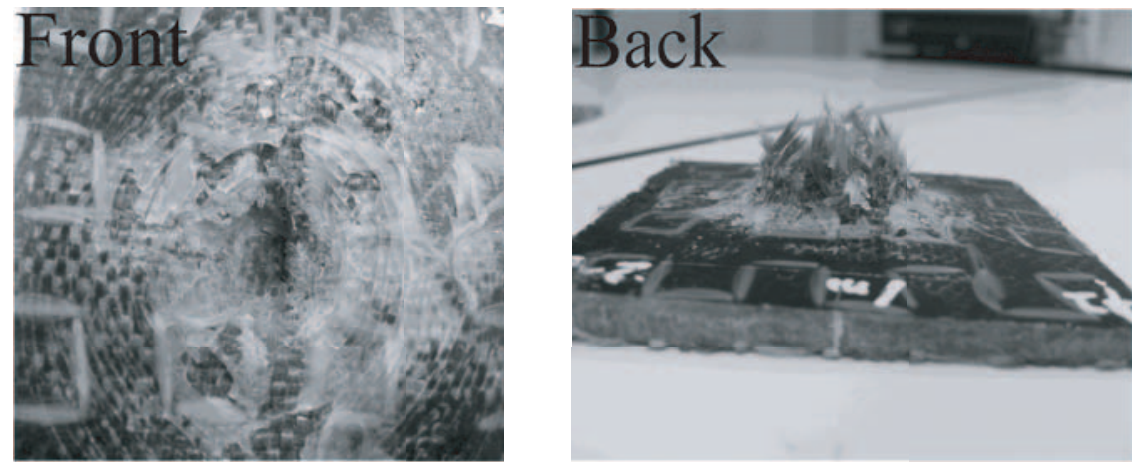

(c)

Figure 9. Impacted samples under different impact speeds: (a) $3.13 \mathrm{~m} / \mathrm{s}$, (b) $3.83 \mathrm{~m} / \mathrm{s}$, and (c) $4.43 \mathrm{~m} / \mathrm{s}$. 


\section{CONCLUSIONS}

3D stitched woven-knitted fabric reinforced composites were manufactured using RTM. Tensile, bending, and impact tests were carried out and corresponding stress-strain, stress-deflection, impact load-displacement, and specific energy-displacement curves were presented. According to the results of this experimental work, it is possible to conclude that:

(a) 3D textile preforms with high mechanical performance and low cost for composite reinforcement can be easily produced by stitching different kinds of 2D textile structures, which have different yarn orientations and fiber volume fractions. 3D preforms used for better resistance against impact can be made by employing the woven fabric structure as the outer layers and knitted fabric structure as the inner layers.

(b) The mechanical properties of 3D stitched woven-knitted composites depend on both 2D woven and knitted structures and their stacking arrangements. Stitching plays an important role in keeping the structural integrity and preventing the composite from delaminations among the different fabric layers.

(c) The tensile behavior of all the 3D stitched woven-knitted composites in the warp direction is better than in the weft direction due to better yarn orientation and distribution in the knitted loops in the warp direction. The composite made with varied plain knit as the inner layers shows the highest Young's modulus, whereas the one with interlock shows the highest tensile strength and energy absorption.

(d) The bending curves with the step-like drops in stress after the initial fracture indicate the break sequence of the fabric layers from the bottom to the upper layers. To avoid the step-like drop, the bottom fabric layer should have higher deformation capability than the inner fabric layers.

(e) The load and energy absorbed increase with an increasing of the impact speed during impacting tests. The composite reinforced with interlock as the inner layers shows the best impact properties due to the tightest structural feature and the fibers oriented in the out-of-plane directions of the composite panel.

\section{ACKNOWLEDGMENTS}

The authors wish to thank the European Commission for awarding research funds under the EU Asia-link program (Project No.82158), the University of Minho in Portugal and Donghua University in China, for providing research facilities.

\section{REFERENCES}

1. Ko, F.K. (1989). Three-dimensional Fabrics for Composites, In: Chou, T.W. and Frank, K.K. (eds), Textile Structural Composites, pp. 129-171, Elsevier Science Publishers, Amsterdam, Oxford, New York, Tokyo.

2. Mouritz, A.P., Bannisterb, M.K., Falzonb, P.J. and Leongb, K.H. (1999). Review of Applications for Advanced Three-dimensional Fibre Textile Composites, Composites Part A: Applied Science and Manufacturing, 30(12): 1445-1461.

3. Weimer, C. and Mitschang, P. (2001). Aspects of Stitch Formation Process on the Quality of Sewn Multi-textile-preforms, Composites Part A: Applied Science and Manufacturing, 32(10): $1477-1484$. 
4. Beier, U., Fischer, F., Sandler, J.K.W., Altstdt, V., Weimer, C. and Buchs, W. (2007). Mechanical Performance of Carbon Fibre-reinforced Composites Based on Stitched Preforms, Composites Part A: Applied Science and Manufacturing, 38: 1655-1663.

5. Mouritz, A.P., Leong, K.H. and Herszberg, I. (1997). A Review of the Effect of Stitching on the In-plane Mechanical Properties of Fibre-reinforced Polymer Composites, Composites Part A: Applied Science and Manufacturing, 28(12): 979-991.

6. Kang, T.J. and Lee, S.H. (1994). Effect of Stitching on the Mechanical and Impact Properties of Woven Laminate Composite, Journal of Composite Materials, 28(16): 1574-1587.

7. Nie, J.J., Xu, Y.D., Zhang, L.T., Yin, X.W., Cheng, L.F. and Ma, J.Q. (2008). Effect of Stitch Spacing on Mechanical Properties of Carbon/Silicon Carbide Composites, Composites Science and Technology, 68: 2425-2432.

8. Yoshimura, A., Nakao, T., Yashiro, S. and Takeda, N. (2008). Improvement on Out-of-Plane Impact Resistance of CFRP Laminates due to Through-the-Thickness Stitching, Composites Part A: Applied Science and Manufacturing, 39: 1370-1379.

9. Lee, G.W., Choi, J.S., Lee, S.S., Park, M., Kim, J.Y., Choe, C.R. and Lim, S.H. (2003). Mechanical Properties and Failure Mechanism of the Polymer Composite with 3-Dimensionally Stitched Woven Fabric, Macromolecular Research, 11(2): 98-103.

10. Colin de Verdiere, M., Pickett, A.K., Skordos, A.A. and Witzel, V. (2009). Evaluation of the Mechanical and Damage Behavior of Tufted Non Crimped Fabric Composites Using Full Field Measurements, Composites Science and Technology, 69: 131-138.

11. Koissiny, V., Kustermans, J., Lomov, S.V., Verpoest, I., Van Den Broucke, B. and Witzelx, V. (2009). Structurally Stitched NCF Preforms: Quasi-static Response, Composites Science and Technology, 69: 2701-2710.

12. Sun, B.Z., Hu, D.G. and Gu, B.H. (2009). Transverse Impact Damage and Energy Absorption of 3D Multi-structured Knitted Composite, Composites Part B: Engineering, 40: 572-583.

13. Zhang, J.W., Hu, H., Sun, B.Z. and Gu, B.H. (2009). Dynamic Responses of 3D Multi-structured Knitted Composite T-Beam Under Transverse Impact, Journal of Composite Materials, doi: 10.1177/002/998309345238. 